\title{
Comparing the Effects of Mutualism and Competition on Industrial Districts
}

\author{
Christopher J.K. Knighte ${ }^{\mathrm{a}, \mathrm{b}}$, Alexandra S. Penn ${ }^{\mathrm{a}, \mathrm{c}}$, Rebecca B. Hoyle ${ }^{\mathrm{b}, *}$ \\ ${ }^{a}$ ERIE, Department of Sociology, University of Surrey, Guildford, GU2 7XH, UK \\ ${ }^{b}$ Department of Mathematics, University of Surrey, Guildford, GU2 7XH, UK \\ ${ }^{c}$ Centre for Environmental Strategy, University of Surrey, Guildford, GU2 7XH, UK
}

\begin{abstract}
Industrial districts are made up of numerous firms or industries interacting in myriad ways. We create and study a model of trade and service interactions in an industrial district, and then extend it to investigate the effect of both positive (mutualistic) and negative (competitive) non-trade interactions on the behaviour of two different types of industrial district - Marshallian and hub-and-spoke. In particular we study whether the structure of the district, or the positioning of the relationships, make a difference to the outcome for the district as a whole.

We find that both these aspects make a difference. For instance, in both Marshallian and hub-and-spoke districts a competitive relationship between firms that are directly linked by trade has a stronger effect than competition between firms that are not. On the other hand in a Marshallian district it is possible to make the district more 'egalitarian' by adding a mutualistic relationship between suppliers or between intermediary firms, but this effect is not seen in hub-and-spoke districts. We highlight for further investigation a hypothesis suggested by our results that the effects of mutualism on an industrial district are more pronounced than those of competition.
\end{abstract}

Keywords: Industrial district, mutualism, competition, trade dynamics 2010 MSC: 91B26, 91B60, 91B74, 91D30

\footnotetext{
* Corresponding author

Email address: r.hoyle@surrey.ac.uk (Rebecca B. Hoyle)
} 


\section{Introduction}

Industrial districts are geographic or economic areas containing numerous interacting firms or industries. For example the Humber region in the UK is a large, active and diverse industrial area on the Humber estuary. The area is centred on the combined ports of Grimsby and Immingham, which together form the UK's largest bulk port by tonnage and part of one of the largest and busiest port complexes in Europe, see [1] and references therein. The region is a net energy exporter, with a large number of fossil-fuel based power stations. The diversity of industries situated in the region include food processing industries, oil refining, chemical and bio-chemical production facilities, as well as heavy industrial facilities such as steel making and cement production. Many of these industries interact with one another, often via the material supply of goods or services. This can range from the unexceptional use of electricity by almost all industries (in most instances procured from energy suppliers via the grid), to industry-specific needs such as biomass for co-firing power plants. These interactions form a complicated web representing the industrial economy of the Humber region.

Obviously such an intricate network of relationships is not unique to the Humber region. In fact, any economy which has a regional component could be represented by a complicated set of interconnections between constituent industries and several fields of study explicity consider industrial districts in this way. Within economic geography, different types of industrial districts have been classified by their distinct network structures (Markusen's work, to which we will return [2], gives a detailed overview and extends the classification scheme). The different district types identified may have more or less complex structures. For instance, "hub-and-spoke" districts are based around one major firm. Such economies are likely to have a relatively simple set of relationships between the industries present; either supplying the major firm or buying and using its products. The district types are considered to have distinctly different whole-system characteristics in terms of stability against risk etc. as a result of both their varying structures and the properties of the individual firms involved.

In the field of industrial ecology the networks formed by the complex interactions and interdependencies between firms in a given locale or within an industrial sector are regarded as "industrial ecosystems" (e.g. [3, 4, 5, 6, 7, 8, 9, 10, 11, 12]). An industrial ecosystem constitutes not only a metabolic network formed by flows of energy and materials, but also formal and informal social networks with economic, contractual and social relationships through which information or money may be considered to flow (e.g. 
[13, 14, 15, 16]). The structure, nature and development of each of these different networks are interconnected and influence that of the others. Thus it is considered that if we wish to understand the dynamics of an industrial ecosystem, we must understand the interplay of these different networks and their individual structures. Ultimately, macroscopic properties of the industrial ecosystem that we are interested in managing, such as carbon dioxide emissions, material throughput, regional Gross Value Added (GVA), or job creation will be the result of these structures and their lower-level dynamics under the influence of regulation and other external factors.

Like industrial ecosystems, biological ecosystems consist of numerous interconnected types of actor, or species, which influence each other positively or negatively via a number of different kinds of interaction [17, 18, 19]. Much work has been done within ecology to study the dynamics of ecological networks and the way that the structure of those networks and distribution of interaction types can affect the outcome for the whole community (e.g. [20, 21, 22, 23, 24, 25]). As industrial networks or ecosystems undoubtedly share some of the structural properties of biological ecosystems it seems likely that some of the tools of ecological modelling could be usefully adapted to industrial ecology.

Additionally, we are particularly motivated to compare some of the most recent thinking about how ecosystem structure and interaction types affect higher-level outcomes for whole ecological networks to industrial ecosystems. This is pertinent as industrial ecology not only considers industrial networks as structures that are in some way similar to biological ecosystems, but also considers ecological networks as models to be emulated. Ecological terminology and concepts are commonly used in this field both to describe extant interactions within industrial systems and as potentially beneficial properties to be engineered or designed in to improve their material sustainability. Attempts are made to promote higher level properties, such as resilience, robustness and high resource cycling levels, claimed to be important for sustainability and often ascribed to ecosystems, via the engineering of interfirm interactions. In particular, the practice and promotion of so-called "industrial symbiosis" is widespread. Industrial symbiosis is generally defined as the reuse or recycling of one or more companies' by-products or waste/excess utilities or services as primary resources within the industrial network to the benefit of both parties [26, 27, 28]. Within ecology we would more properly refer to this as a mutualism, as symbiosis (or living together) refers to a close and long-standing biological association of any type between two or more species [29]. Such interactions may be mutualistic (both partners benefit), commensualistic (one partner benefits whilst the other experiences no signif- 
icant effect) or parasitic (one partner benefits to the detriment of the other). Despite this slight mismatch in use of terminology, a rigorous investigation of the effects of distribution of mutualisms and other types of bipartite interaction within an industrial ecosytem in conjunction with the different possible industrial network structures could be timely and useful in testing assumptions on how lower-level changes affect system-level properties.

In the early days of industrial ecology results were imported directly from community ecology as heuristics to guide action. Many more modern approaches have moved away from ecology per se however. The dynamics of industrial ecosystems have been extensively modelled with agent-based models (ABMs) ([30, 31, 32, 33]), as ABMs combined with material flux analyses or life cycle analysis [34, 35, 36], or combined in multi-level models within dynamic optimization frameworks [37, 38]. The structure of industrial ecosystems has also been analysed with tools from network analysis [39, 40, 41, 42], although evolution here has simply constituted study of snapshots of structure over time rather than the simulation of interaction dynamics on a network. Others have discussed the evolution of industrial networks within qualititative frameworks either drawn from ecology-inspired fields such as the resilience movement, or of their own devising (see [11, 43] for example). In the meantime, theoretical ecology has made great strides forward. However, the connection between insights from ecology and industrial ecology has failed to progress apace [12]. (Although static comparisons have been performed between the connectance of industrial networks and food webs as a first step in reinstigating this link [44].) We believe that this connection could still yield something useful by testing some of the basic tenets of industrial ecology against new knowledge and potentially informing practical action. Recent work on the combined effect of network structure and inter-species interaction types on whole network properties is a case in point.

Recent results have shown that there are substantial differences between the resilience and persistence of networks of mutualists and trophic networks depending on the network structure. In [45] Thébault and Fontaine studied two types of species interaction dynamics: mutualistic (pollinator-plant) and trophic (predator-prey) on various model and empirically observed networks. They found that "Higher diversity and connectance promote the persistence and resilience of mutualistic networks, but they destabilize trophic networks. For mutualistic networks, modularity decreases the persistence of the network, and nestedness increases its resilience. In contrast, for trophic networks, nestedness decreases the persistence of the network, and modularity enhances its resilience" [45, p. 855]. The practice of industrial symbiosis 
has been supported by legislation in the UK with initiatives such as the National Industrial Symbiosis Programme [46]. Whilst the reductions in material sent to landfill and carbon dioxide emissions are of course enormously beneficial in their own right, the non-additive effects of changing the distributions of interaction types within industrial ecosystems may have unexpected effects. Mutualisms embedded within regional trade networks are commonly assumed to enhance desirable whole-network properties such as resilience and persistence. However Thébault and Fontaine have demonstrated that, in ecological networks at least, this picture may be more nuanced. Network structure as well as interaction type matters in ecosystems. It seems likely that the effect of encouraging mutualisms within industrial ecosystems will also vary according to the structure of the industrial network in which such policy is applied. Taking an ecological modelling approach as our inspiration, we propose to investigate the differences in dynamics caused by mutualistic and competitive relationships within industrial ecosystems. However, rather than focussing on network properties such as modularity, connectance and nestedness which have been studied in ecosystems, we will use the network structures of different industrial district types as the context within which to explore these effects.

Much research has been carried out on food webs and how to model them in a quantitative, whole system, manner. The archetype of whole system ecology models is the Lotka-Volterra model for predator-prey interactions, originally developed by Lotka in the 1920s [47]. This is a dynamical population-based model with the change in population of each individual species being represented by a differential equation. Each equation contains terms relating to population growth, for instance birth rates, which could be related to the availability of food, and hence to the population of any prey species. Each equation also contains a term representing the decrease in population due to death. This term may be dependent on the size of predator populations. The way that the growth and decay terms depend on the population sizes of other species couples all of the equations together, creating a simple model of the complete food web. Variants of this basic Lotka-Volterra model have been applied to model many different food webs [48, 49]. Inspired by Thébault and Fontaine's use of a Lotka-Volterra model to describe the dynamics on the mutualistic and trophic networks that they studied [45], we use a similar type of model to describe the interaction between firms or industries in an industrial district, in order to explore the relationship between industrial network structure and the effects of mutualism and competition in a similar framework. Instead of each equation modelling the size of a population of a particular species we instead create 
an equation for the 'size' of each firm or industry, where 'size' can be thought of as an abstract concept that in some way represents the health and wealth of a firm. (Such a measure has previously been used to identify the presence of mutualism or competition between firms in a single sector [50].) The coupling of these equations is then via the 'size' of supplier and customer firms rather than prey and predator populations. This dynamical model of the interactions of industries in a economic or geographic district will be quite high level and general without going into many of the specifics considered when modelling individual supply chains. The idea behind the model is not to give intricate detail about the system but rather represent it with a 'broad brush' in order to make statements on the scale of the whole system, and how it might respond to changes.

As well as trade relationships there are also what we might call social interactions, both positive and negative. For instance, joint bidding for funding, information sharing around regulation, competition for scarce, highly skilled workers, etc. For instance, the Humber region is of national and international biodiversity and conservation importance and industries may co-operate on issues of mutual concern regarding consequent development legislation. Also, neighbouring communities face significant socio-economic problems, meaning that there is likely to be a high level of competition for highly skilled workers. We extend our model to incorporate such non-trade interactions, in particular focussing on dyadic relationships (although other relations can be approximated as a collection of dyadic relationships).

As has already been mentioned there is a plethora of different forms of non-trade interactions, far too many to model coherently. Instead we split the interactions down into two dichotomal types and model each of these types from an archetypal example. The two types of interactions that we consider are those which produce a benefit to both parties in the relationship, so called mutualistic relationships, and those which are detrimental to the two parties, so called competitive relationships. There are several different forms of (non-trade) mutualistic and competitive relationships. Examples of mutualistic relationships include information/knowledge sharing, client referral, joint training, joint infrastructure for CHP (combined heat and power), and joint bidding for external funding. Correspondingly, examples of competitive interactions (excluding those due solely to trade) may include the situation where there is competition for scarce highly skilled workers. Another example may be reciprocated animosity between the chief executives of two firms, leading to decisions which may not be in the best interest of the firm but would 'hurt' the other firm (for instance, buying patents that they have no use for, simply to stop the other firm producing a product). 
In general there may be several non-trade interactions of each type forming two different networks.

As a result of including these mutualistic and competitive relationships the model now consists of dynamics on three interrelated networks. That is, the model will span and link three different networks of the industries in a district: the trade network, the mutualistic (non-trade) network, and the competitive (non-trade) network. This makes it hard to isolate the effects of mutualism and competition on the dynamics of the system as a whole. To investigate the effects of competition and mutualism we therefore look at subclasses of the networks. For instance before investigating an arbitrary mutualistic network it makes sense to investigate the impact of a single mutualistic link in an arbitrary position. Whilst we can use this approach for the mutualistic and competitive networks we still need to constrain the trade network in some manner. We do this by considering two distinct types of industrial district, Marshallian districts, and hub-and-spoke districts [2].

A Marshallian district is "comprised of small, locally owned firms that make investments and production decisions locally...within the district, substantial trade is transacted between buyers and sellers" [2, p. 297]. A typical example of such a district is that of Italian artisan shoe makers. In general supplies come from outside the locale and the end product is also sold outside the district. Within the district many of the artisan producers have the same suppliers and customers. In terms of a network, Marshallian districts are highly connected feed-forward networks, see the left panel of Figure 1. The architecture of a hub-and-spoke district is quite different, right panel of Figure1. As the name implies, it consists of one central firm (maybe part of a global conglomerate) with lots of local suppliers and customers, as well as suppliers and customers that are not part of the local district. Some of these suppliers may have suppliers of their own within the district, and some of the customers, customers of their own. In this paper however, we shall use the terminology 'hub-and-spoke district' to refer solely to the case where the customers of the hub have no customers themselves in the network. From a network perspective this network is again a feed-forward network. The hub is itself both a primary supplier and an end consumer and so there is no overlap between the definitions of the Marshallian and hub-and-spoke districts. The Marshallian and hub-and-spoke networks are archetypes that capture distinctive characteristics of particular types of trade networks [2]. However, real trade networks, such as that in the Humber region, will typically be more complicated than a single archetype - perhaps combining aspects of several - and may have more complex connectivity, for example incorporating loops. 


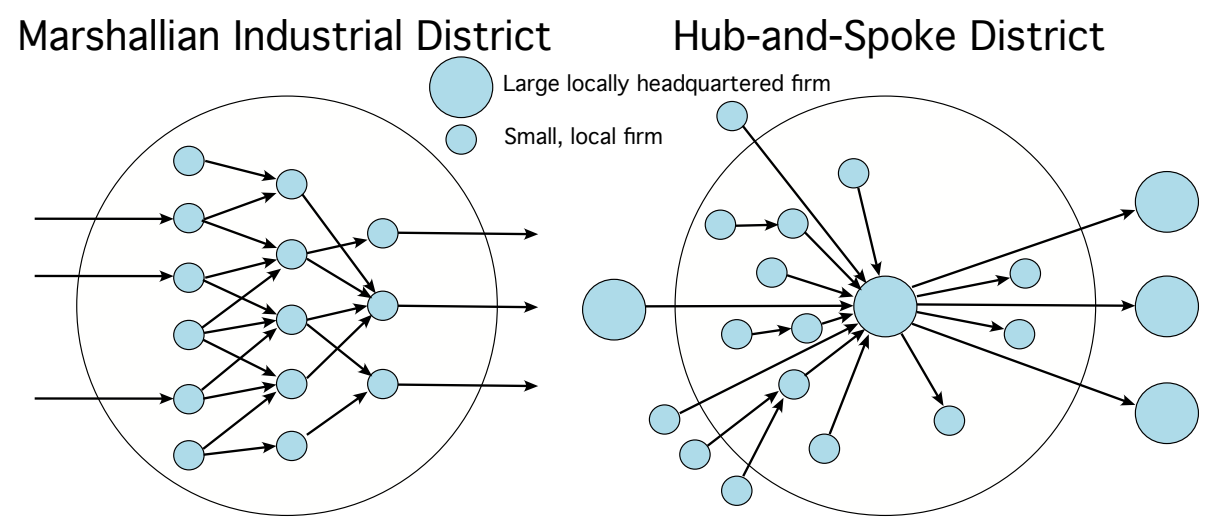

Figure 1: Marshallian, and hub-and-spoke districts, following Figure 1 of [2].

In this paper we investigate the effect of mutualistic and competitive connections on the dynamics of Marshallian and hub-and-spoke districts. Drawing inspiration here from the ecology literature where it has been seen that the structure of the ecological web influences which types of dynamics are stable, we expect that the effects of mutualism and competition will be different on these two different types of industrial district.

\section{A Dynamical Model of Trade Relationships}

An industrial economy is made up of numerous different firms or industry types interacting in various ways, in a spatially confined region. As an initial attempt to model the dynamics of such a district of industrial types we shall only consider trade interactions, consisting of the trade in goods and services. Further, we shall make the model as simple as possible so that modifications to include social interactions may be made and the model remain amenable to analysis. This means, among other things that the model shall concern only one good (locally), or equivalently make the assumption that all goods (sold within the district) are interchangeable. This assumption is obviously a great simplification of the reality, but leads to a reasonably simple first model and allows us to find the data needed to initialise the model. It would be possible to make the model more complicated; however there is a trade-off with its usability. The aim of the model is to express the general behaviour of the system as a whole, as simply as possible, and in that context the level of assumptions made is appropriate.

As no spatially confined industrial economy (an industrial district) is closed there will always be flows of materials and services into and out 
of the district. Similarly unless we model on the scale of the individual there will be transactions between entities in the model and those which have not been modelled, for instance individual consumers. To account for this edge of the district we split the industry types into three categories signifying their relationship with what lies beyond the district. They are denoted 'primary suppliers' (S), 'intermediaries' (I) and 'end consumers' (C). The distinction relates to the structural role of each firm, both the 'primary suppliers' and the 'end consumers' have some form of trade link with entities beyond those modelled in the local district. The rest of the firms are denoted 'intermediaries'. The 'primary suppliers' are those firms who derive product from somewhere outside of the network. For instance, if a local network is considered then any firm which buys material from further afield is denoted a 'primary supplier'. Additionally a firm which mines for or otherwise produces resources (as long as the resource itself is not modelled) is a 'primary supplier'. 'End consumers' are those firms who sell product beyond the network. This can either be thought of as global trade when considering a local network or as selling of product to individual customers (people or small firms not included in the model). It is important to recognise that a 'primary supplier' may also buy from other firms in the network. Similarly 'end consumers' may supply other nodes in the network. It is also possible for a firm (or industry) to be both a 'primary supplier' and an 'end consumer', in this case the firm is called a hub of the network. Figure 2 shows an example of a local trade network with labels denoting the type of each node. Note that every node must be connected (backward) to at least one supplier and connected (forward) to at least one consumer. A node with no outgoing connections to other nodes in the network is automatically an 'end consumer', and one with no incoming connections from other nodes in the network is automatically a 'primary supplier'.

With this distinction we can start formulating our model for the interactions of industries in a region. We shall start by considering the industries denoted 'intermediary'; the equations for industries of the other two classes can be easily derived from them. Each intermediary (by definition) will have suppliers and customers amongst the other firms (industries) that make up the model. For a specific firm denoted 'firm $i$ ' the set of firms which supply products or services to it is denoted $S_{i}$, and the set of firms which buy products or services from firm $i$ is denoted $C_{i}$. At its most basic our model says that each year a firm or industry grows by the amount it sells its products and services for, less the amount it spent buying the raw materials or services it needed, less overhead costs. However actually writing this basic model down proves to be fairly complicated. 


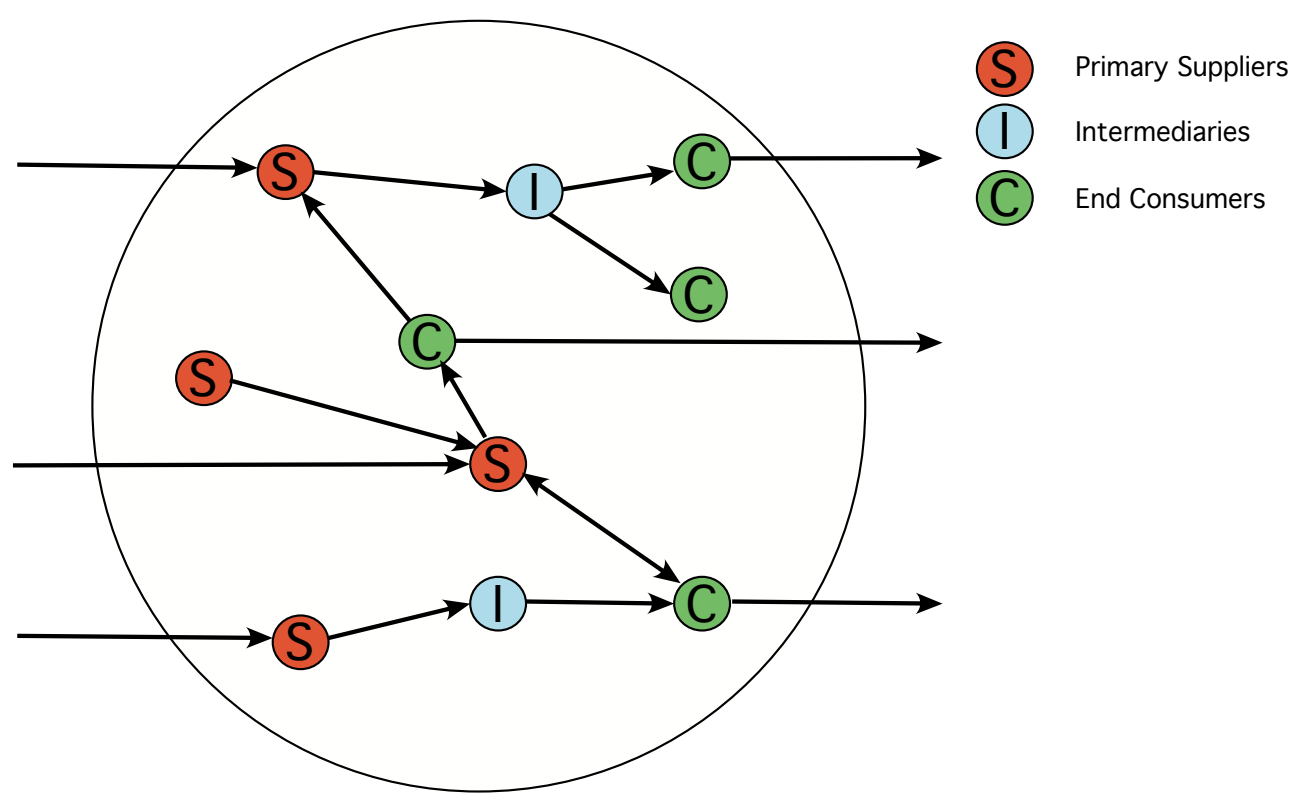

Figure 2: An example network with nodes marked as S: 'primary supplier', I: 'intermediary', C: 'end consumer'.

We denote the wealth/health/general utility of firm $i$ by $u_{i}$, and the worth of the products or services sold to firm $j$ by firm $i$ by $G\left(u_{i}, u_{j}\right)$. The worth of a product (or service) will be different to those selling it and those buying it. We model the cost to a firm $i$ 's utility of buying from firm $j$ as $G\left(u_{j}, u_{i}\right)$ and the gain to firm $i$ 's utility of selling to firm $j$ as $\left(1+\epsilon_{i}\right) G\left(u_{i}, u_{j}\right)$, where $\epsilon_{i}$ is the percentage profit that firm $i$ makes. Finally, if we denote the percentage overhead costs of firm $i$ by $d_{i}$ then the basis of our model can be written:

$$
\dot{u}_{i}=\left(1+\epsilon_{i}\right) \sum_{j \in C_{i}} G\left(u_{i}, u_{j}\right)-\sum_{j \in S_{i}} G\left(u_{j}, u_{i}\right)-d_{i} u_{i} .
$$

This equation forms the basis of our model, and is almost complete for intermediary firms. The one major component still to add is the effect on the utility if a firm is not able to buy all of the materials or services it requires. This could affect the amount of its own product a firm is able to sell, however this soon gets very complicated and would require the use of delay equations. Instead we assume that the same amount of product (or service) is made but it costs more or is of lower quality. For instance, buying in the completed product from some external supplier at market rates to ensure the firm has 
enough product to sell in the short term. This would not change the worth of the product to the customer, but would certainly affect the worth to the supplier. We model this by imposing a multiplicative penalty term $\mathcal{P}_{i}$ on the gain in utility given by the selling of product. This penalty is modelled as the ratio of the actual supply of material and services to the total required supply. Thus our model for the health/wealth of a firm becomes

$$
\dot{u}_{i}=\left(1+\epsilon_{i}\right) \sum_{j \in C_{i}} G\left(u_{i}, u_{j}\right) \mathcal{P}_{i}-\sum_{j \in S_{i}} G\left(u_{j}, u_{i}\right)-d_{i} u_{i} .
$$

The details required to make (2) a complete model are expressions for the value of product sold between firms, $G\left(u_{i}, u_{j}\right)$, and the multiplicative penalty term, $\mathcal{P}_{i}$. There are different ways to do this, including full market modelling in the case of the amount of product sold between firms. However we shall again choose a simpler option. We shall assume that there is a fixed percentage of the utility that a firm requires in supplies, $\beta_{i}$. That is $\beta_{i} u_{i}$ is the total amount that firm $i$ must 'pay' to buy all of the materials and services it needs when it has grown to size $u_{i}$. Similarly we assume that the value of the product each firm creates is proportional to its size $u_{i}$. That is a firm with utility $u_{i}$ produces products with a value $\rho_{i} u_{i}$. A complete list of all the notation used in our model is given in Table 1. With this notation we can express the penalty term (still for intermediary firms) as

$$
\mathcal{P}_{i}=\frac{\sum_{j \in S_{i}} G\left(u_{j}, u_{i}\right)}{\beta_{i} u_{i}}
$$

the fraction of the required supply that a firm actually managed to procure. The expression we use for $G\left(u_{j}, u_{i}\right)$ is more complicated as firm $i$ is likely to have multiple suppliers and each of them is likely to have multiple customers. If each firm that supplies firm $i$ can meet all demands for product placed upon them by all of their customers (i.e if they're big enough) then firm $i$ is able to buy the total amount of product it requires, $\beta_{i} u_{i}$. We assume that the amount it buys from each of its suppliers is proportional to their size (utility). This expresses the desire to keep the largest of a firm's suppliers as happy as possible without totally alienating any of the other suppliers. That is, if all of a firm's suppliers are able to fulfil the entire demand for product placed upon them, we have

$$
G\left(u_{j}, u_{i}\right)=\beta_{i} u_{i} \frac{u_{j}}{\sum_{k \in S_{i}} u_{k}} .
$$

If on the other hand one of firm $i$ 's suppliers (firm $j$ say) is unable to fulfil the total demand placed upon it then it will supply the maximum total 
amount that it can: $\rho_{j} u_{j}$. It will distribute this according to the demand placed on it by each of its customers. We again assume that it sells in proportion to the amount each customer requires (see above), in order to retain the largest customers without alienating any of the smaller customers. (Note in our model we do not allow the customers or suppliers of firms to change, although they can go out of business.) That gives

$$
G\left(u_{j}, u_{i}\right)=\rho_{j} u_{j} \frac{\beta_{i} u_{i} \frac{u_{j}}{\sum_{k \in S_{i}} u_{k}}}{\sum_{l \in C_{j}}\left[\beta_{l} u_{l} \frac{u_{j}}{\sum_{m \in S_{l}} u_{m}}\right]} .
$$

Combining these two scenarios gives:

$G\left(u_{j}, u_{i}\right)=\left\{\begin{array}{cl}\beta_{i} u_{i} \frac{u_{j}}{\sum_{k \in S_{i}} u_{k}} & \text { if } \sum_{l \in C_{j}}\left[\beta_{l} u_{l} \frac{u_{j}}{\sum_{m \in S_{l}} u_{m}}\right] \leq \rho_{i} u_{i}, \\ \rho_{j} u_{j} \beta_{i} u_{i} \frac{u_{j}}{\sum_{k \in S_{i}} u_{k}} \frac{1}{\sum_{l \in C_{j}}\left[\beta_{l} u_{l} \frac{u_{j}}{\sum_{m \in S_{l} u_{m}}}\right]} & , \text { otherwise. }\end{array}\right.$

This completes the details of the model for intermediary firms. We now explain the amendments needed to cope with the 'primary suppliers' and 'end consumers'. First of all note that if the current model (2) were applied to an end consumer with no customers being modelled then there would be no growth term, and so $u_{i}$ would be monotonically decreasing. Similarly looking at a primary supplier the only negative term would be the overheads, even though products were being bought and paid for from outside the set of firms modelled. To counter this we add an extra term to the model containing the utility gain or loss from exporting or importing, respectively, materials and products from outside the set of firms modelled. We denote this component of the model $\Lambda_{i}$, and its value depends on the classification of the firm. If firm $i$ is an intermediary firm then $\Lambda_{i}=0$. We assume that the supply of a product from outside the district is essentially unlimited. That is, a firm which is a supplier can buy all of what it requires, $\beta_{i} u_{i}$, from outside the district. If a firm buys all of its supplies from outside the district then using the total value $\beta_{i} u_{i}$ makes sense. However if it buys some of its supplies from inside the district it would end up buying supplies to the value of $2 \beta_{i} u_{i}$. If this is the case we make the value of $\beta_{i}$ half what it would otherwise be. Whilst the choice of a half of the product being bought from within the district and half from outside of the firms modelled is arbitrary, 
it is something which could easily be improved upon in later iterations of the model if such detailed data is available.

When considering 'end consumers' we make the assumption that the external market for the products and services being created is bounded: the total maximum demand of the external market is for products with value $M$. If the total amount the district is trying to sell to the external market exceeds the market demand then each end consumer sells according to their size.

Thus the amount 'end consumer' $i$ sells to the external market is

$$
\tilde{G}\left(u_{i}\right)=\left\{\begin{array}{cl}
\rho_{i} u_{i} & , M>\sum_{j \in \mathbf{C}} \rho_{j} u_{j}, \\
M \frac{u_{i}}{\sum_{j \in \mathbf{C}} u_{j}} & , \text { otherwise. }
\end{array}\right.
$$

Again if a firm is an 'end consumer' but also sells to other firms in the district then we make $\rho_{i}$ half of what it would otherwise be. If firm $i$ is an 'end consumer' its utility needs to increase by $\left(1+\epsilon_{i}\right) \tilde{G}\left(u_{i}\right)$. That is we have

$$
\Lambda_{i}=\left\{\begin{array}{cl}
-\beta_{i} u_{i} & , i \text { a primary supplier } \\
0 & , i \text { an intermediary } \\
\left(1+\epsilon_{i}\right) \tilde{G}\left(u_{i}\right) & , i \text { an end consumer, } \\
-\beta_{i} u_{i}+\left(1+\epsilon_{i}\right) \tilde{G}\left(u_{i}\right) & , i \text { a primary supplier and an end consumer. }
\end{array}\right.
$$

Finally we must deal with the multiplicative penalty term due to lack of supply for 'primary suppliers' and 'end consumers'. As it is assumed that there is no limit to the amount 'primary suppliers' (including hubs) can procure from outside the district, no penalty due to lack of supply will be imposed. In the case of an 'end consumer' (but not a hub) the penalty term will be the same as for the intermediary firms. However the penalty is applied to the $\Lambda_{i}$ term as this is now the term which incorporates the benefits to the utility from selling products or services. That is

$$
\mathcal{P}_{i}=\left\{\begin{array}{cl}
1 & , i \text { a primary supplier } \\
\frac{\sum_{j \in S_{i}} G\left(u_{j}, u_{i}\right)}{\beta_{i} u_{i}} & , \text { otherwise. }
\end{array}\right.
$$

Thus our model for the trade interactions of firms or industries within a local district is

$$
\dot{u}_{i}=\left(1+\epsilon_{i}\right) \sum_{j \in C_{i}} G\left(u_{i}, u_{j}\right) \mathcal{P}_{i}-\sum_{j \in S_{i}} G\left(u_{j}, u_{i}\right)+\Lambda_{i} \mathcal{P}_{i}-d_{i} u_{i} .
$$

The notation is summarised in Table 1 


Symbol Definition
\begin{tabular}{|c||l|}
\hline$\Lambda_{a}$ & The intrinsic growth rate (seen from a local perspective) of firm $a$. \\
\hline $\mathcal{P}_{i}$ & The penalty to firm $i$ of not buying enough product. \\
\hline$G(a, b)$ & The worth of product $a$ that is bought by firm $b$. \\
\hline$\beta_{a}$ & The value of the material or services that $a$ needs as a proportion of its wealth. \\
\hline$\rho_{a}$ & The value of $a$ 's product or service as a proportion of its wealth. \\
\hline$\epsilon_{a}$ & The percentage profit made by firm $a$. \\
\hline$d_{a}$ & Percentage upkeep costs of firm $a$. \\
\hline$M_{k}$ & The maximum value of product type $k$ which the district can sell externally. \\
\hline
\end{tabular}

Table 1: List of Notation

We would like to investigate the dynamics of this model, and to do that we must parameterise the system. Due to the large number of parameters and variations in the structure of trade networks it is impossible to look at them all in the detail necessary for a complete analysis. In order to proceed, therefore, we must restrict the cases to be investigated. The first restriction that we shall make is to set the parameters for all of the different firms to the same values. This leaves six parameters including the initial value of the utilities. To find representative values for these parameters we take the average values over a wide variety of industry types. Specifically we take the average of the values derived from empirical data in [51] for a trade network in the Humber region. This gives values of $\beta=0.0786, \rho=0.3732$, $\epsilon=0.3680$ and $d=0.0560$. We rescale the value of $M$ derived in [51] to allow us to take $u_{0}=1$ as the initial condition and to take into account the number of end consumers in a district. That is, we divide the value found in [51] by the number of consumers in that district (10) and then by the average utility of all firms to give $M=1377.7422 / 717.0284 \times$ number of end consumers $=$ $1.9215 \times$ number of end consumers.

Typical dynamics for the system show initial growth of the utility of firms, followed by decline for some firms and stabilisation for others. Figures 3 and 4 show the dynamics for the Marshallian and hub-and-spoke networks in Figure 1, for identical initial conditions for all firms and for a set of nearby uniformly distributed random initial conditions. Note that although the outcomes from the identical and randomised initial conditions look different, with the firm utility trajectories being spread out in the randomised case, as opposed to groups of trajectories being superimposed in the case of identical initial conditions, exactly the same firms survive in each case for both networks, suggesting that the dynamics are in fact fairly robust 
to small changes.

\subsection{Incorporating Non-Trade Interactions}

To incorporate non-trade relationships in our model (44) we simply add the effect of the relationship to the change in health/wealth. As mentioned in the introduction, we consider two types of interaction, mutualism and competition, and their associated networks. We model the behaviour of these two types of non-trade interaction using an archetypal example. For mutualistic relationships we use information/knowledge sharing, and for competitive relationships we use competition for scarce highly skilled workers.

An information/knowledge sharing initiative may consist of members from each firm meeting up monthly to discuss ideas. In such a scenario the cost to each firm is roughly the same and is independent of the health/wealth (size) of the firm. On the other hand it may be thought that the benefit to each firm is proportional to the total amount of knowledge that there is to be shared, which in turn is roughly proportional to the joint size of the firms participating. As we are modelling all interactions as dyadic we must be aware of the discrepancies that this approach gives rise to. More complicated relationships such as a three-firm joint enterprise can be roughly modelled via a complete graph of dyadic relations, however the cost/benefit profile will be slightly wrong. For instance if cost is independent of a firm's size then the dyadic relationships impose that the company pays twice as much as it should (although this will be true for all of the firms in this partnership). Similarly if benefit is proportional to the combined size then, using dyadic relationships, the size of the firms is taken into account more than once, and the benefit to all firms is also doubled. In this paper we shall ignore this issue and only deal with this simpler form of non-trade interaction. For a dyadic mutualistic relationship between two firms ( $a$ and $b$ ) the cost is independent of size whilst the benefit is proportional to the combined size $\left(u_{a}+u_{b}\right)$. Thus we model the mutualistic relationship (in the absence of any trade relationship) with the following system of equations.

$$
\begin{aligned}
& \dot{u}_{a}=F_{a}\left(u_{a}, u_{b}\right) \equiv-C_{a}^{b}+B_{a}^{b}\left(u_{a}+u_{b}\right) \\
& \dot{u}_{b}=F_{b}\left(u_{a}, u_{b}\right) \equiv-C_{b}^{a}+B_{b}^{a}\left(u_{a}+u_{b}\right),
\end{aligned}
$$

where $C_{i}^{j}>0$ is the fixed cost of mutualism with firm $j$ for firm $i$ and $B_{i}^{j}>0$ is the unit benefit to firm $i$ from mutualism with firm $j$. In the absence of any other connections this relationship would lead to an exponential increase in the utility of the two firms involved in the mutualistic relationship. If other relationships (trade or competitive) are present then the dynamics 


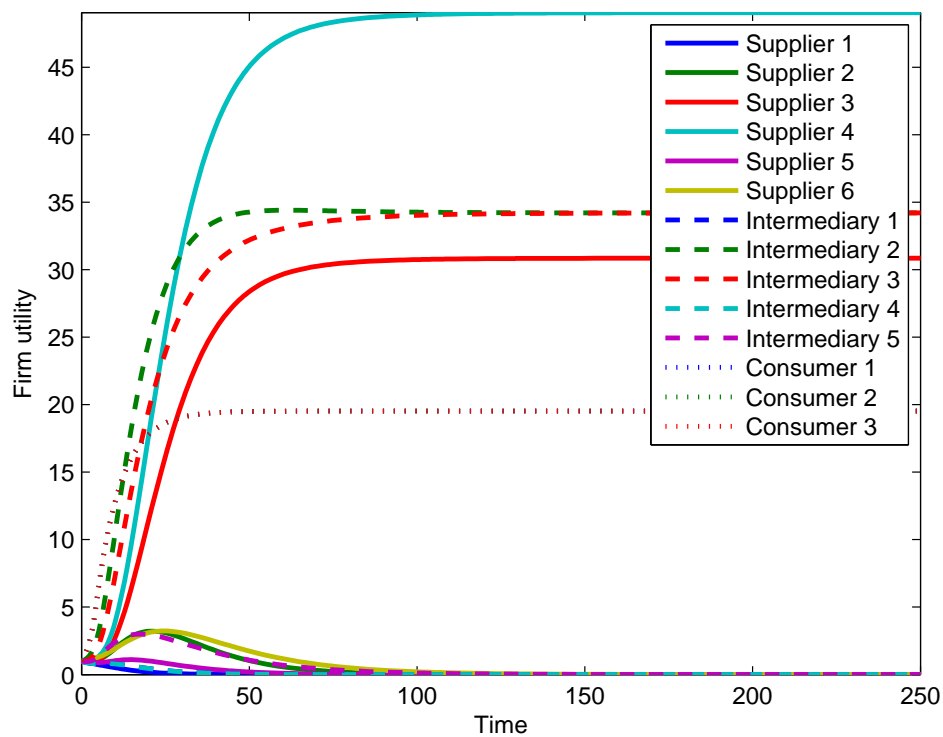

(a)

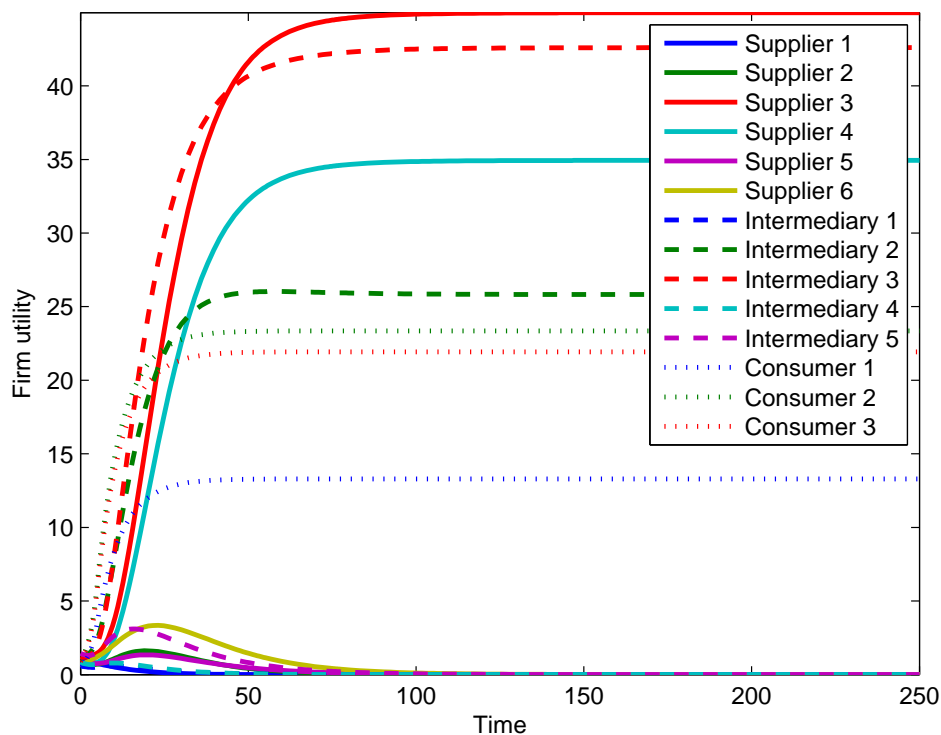

(b)

Figure 3: Trade dynamics on the Marshallian network shown in Figure 1 for (a) identical initial conditions $u_{i}(0)=1$ for all firms and (b) initial conditions uniformly distributed about 1: $u_{i}(0) \sim \mathcal{U}(0.5,1.5)$. Parameter values are described in the text. 


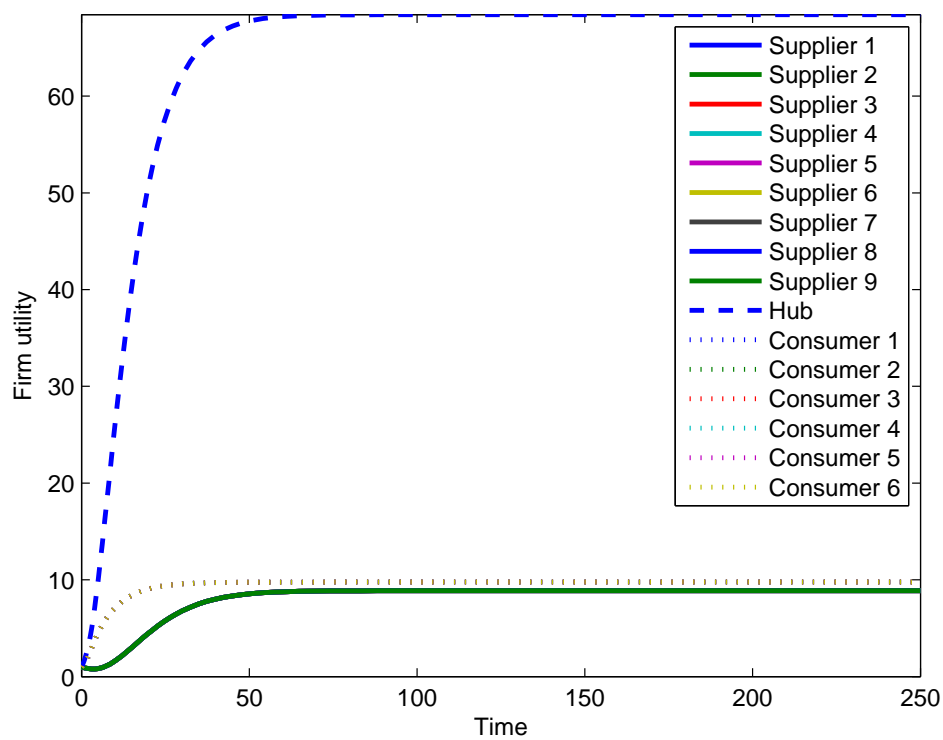

(a)

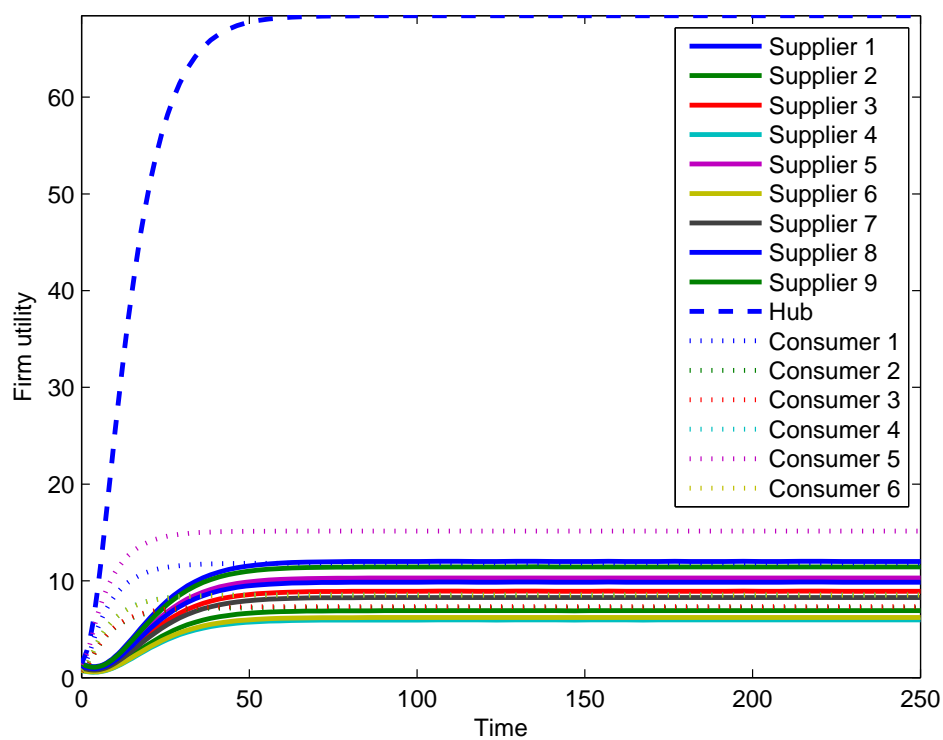

(b)

Figure 4: Trade dynamics on the hub-and-spoke network shown in Figure 1 for (a) identical initial conditions $u_{i}(0)=1$ for all firms and (b) initial conditions uniformly distributed about 1: $u_{i}(0) \sim \mathcal{U}(0.5,1.5)$. Parameter values are described in the text. 
is likely to be more complex. In such cases, to avoid the possibility of a mutualistic relationship turning into a parasitic one (one firm benefiting from the relationship at the expense of the other firm) we set $F_{a}=F_{b}=0$ if $F_{a} F_{b}=0$. That is if firm 'a' starts losing out from the presence of the relationship with firm ' $b$ ', because their combined size become too small so that $F_{a}<0$, then firm 'a' would stop the relationship meaning that $F_{a}=0$ and $F_{b}=0$. The transition from the relationship providing a benefit to imposing a cost occurs when either $F_{a}=0$ or $F_{b}=0$, i.e. when $u_{a}+u_{b}=$ $C_{a}^{b} / B_{a}^{b}$ or $u_{a}+u_{b}=C_{b}^{a} / B_{b}^{a}$.

To model the competitive relationships we say that the firms involved receive no benefit from the relationship, and that the cost is proportional to the size (health/wealth) of the competitor firm. So if we consider two firms, $a$ and $b$ purely in competition with each other then

$$
\begin{aligned}
& \dot{u}_{a}=-c_{a}^{b} u_{b} \\
& \dot{u}_{b}=-c_{b}^{a} u_{a},
\end{aligned}
$$

where $c_{i}^{j}>0$ is the unit cost to firm $i$ of competition with firm $j$. Like mutualism we only consider competition when both firms have non-negative values of $u$. In the absence of other interactions this means that both firms will shrink. As they shrink one value of $u_{i}$ will eventually reach zero, and when this happens we set $\dot{u}_{a}=0=\dot{u}_{b}$. Essentially, in the presence of competition only, one firm dies out whilst the other survives at its expense.

Incorporating the dynamics for mutualistic and competitive relationships, the extended model including trade and non-trade interactions is formed of three networks: a directed one of the trade interactions, an undirected mutualistic network, and an undirected competition network; and the following dynamics:

$\dot{u}_{i}=\left(1+\epsilon_{i}\right) \sum_{j \in C_{i}} G\left(u_{i}, u_{j}\right) \mathcal{P}_{i}-\sum_{j \in S_{i}} G\left(u_{j}, u_{i}\right)+\Lambda_{i} \mathcal{P}_{i}-d_{i} u_{i}+\sum_{j \in M u_{i}}\left[B_{i}^{j}\left(u_{i}+u_{j}\right)-C_{i}^{j}\right]-\sum_{j \in C o_{i}} c_{i}^{j} u_{j}$,

where $M u_{i}$ is the set of firms in a mutualistic relationship with firm $i$, and $\mathrm{Co}_{i}$ is the set of firms in a competitive relationship with firm $i$.

In the remainder of this paper we use this model to investigate the effect non-trade interactions have on the dynamics of various types of industrial district. In order to do this we consider simple cases comprising a trade network and either a competitive interaction or a mutualistic interaction. Investigating more complicated mutualistic and competitive networks cannot easily be performed in a systematic manner. Instead we consider the 
results found from the simplest cases to suggest what the effects of more complicated interactions might be.

\section{The Effects of Mutualism and Competition}

As mentioned in the introduction we shall use two types of industrial district to investigate the effect of mutualism and competition on the dynamics: a Marshallian district, and a hub-and-spoke district (Figure 1). We study the simplest form of non-trade network, that is a single mutualistic or competitive relationship between two firms. We shall also study whether the positioning of this relationship has an impact on the dynamics. To do this we look at several different structural classes for the position of the non-trade relationship relative to the underlying trade network. This will allow us to make suggestions that may be relevant to real life Marshallian or hub-and-spoke districts.

To define some of the positions for a non-trade connection we use the classification of the firms as primary suppliers, intermediaries, or end consumers. The positions that we shall use in our analysis are as follows:

- Along a pre-existing trade link.

- Not along a pre-existing trade link. That is, there is no trade connection between the two firms that are in the mutualistic/competitive relationship.

- Between two primary suppliers.

- Between two intermediaries.

- Between two end consumers.

- Between a primary supplier and an intermediary.

- Between a primary supplier and an end consumer.

- Between an intermediary and an end consumer.

These positions are not mutually exclusive: for example a link can be preexisting and also connect a supplier and an intermediary.

To deal with the differences in structure of the trade network that are possible we shall make a restriction to look only at networks with a set number of nodes. For our analysis we shall restrict to studying the effect of mutualism and competition on networks that have 12 nodes. This gives 
a fairly small network on which the model dynamics run in a computationally accessible time and provides us a reasonably simple framework in which to analyse the effect of competitive and mutualistic interactions. For Marshallian districts we also specify a set number of edges, 20, so that the network is not sparsely connected, and may for certain parameter values have all possible connections present. We choose to fix these choices, leaving aside for now the question of sensitivity to the choices themselves, in order to maintain focus on our main topic of investigation, namely mutualism and competition. Of course there are many possible sensitivity analyses that could be performed. However the general form of the trade dynamics - growth of utility followed by decline for some firms and stabilisation for others - appears to be quite consistent and we do not expect to see regime changes or bifurcations in the dynamics.

We still have the freedom to choose how many of the nodes are primary suppliers and how many are end consumers (and implicitly, how many are intermediaries). Depending on this choice the Marshallian networks will range from having all of the connections possible to having about half of the connections possible. In the case of one supplier and one consumer, there are only 20 possible connections to choose from, and so all connections will be present. On the other hand if there are, for example, three suppliers and three consumers then there are 36 possible connections to choose from, and so only just over half are present. For a hub-and-spoke district (with a single hub) specifying the number of primary suppliers, end consumers and nodes automatically specifies the number of edges. We shall treat the number of primary suppliers, $n s$, and the number of end consumers, $n c$, as parameters to be varied in our simulations. As we have fixed the number of nodes (and edges in the Marshallian case) the possible values of these parameters form a fairly small closed set, and so we shall run our dynamical model on a random ensemble of 100 instances of each district type for each possible combination of $n s$ and $n c$.

We use the same parameter values for the trade dynamics as in the previous section. The only remaining freedom is the choice of the parameters associated with the mutualistic network, $C_{i}^{j}$ and $B_{i}^{j}$, and with the competition network, $c_{i}^{j}$. Due to the difficulties arising from the number of possible network structures, mentioned previously, we only look at the addition of a single mutualistic or competitive link. As such we do not expect that making the further restriction $C_{i}^{j}=C, B_{i}^{j}=B$ and $c_{i}^{j}=c$ for all $i$ and $j$ will significantly affect the applicability of our results. Specifically, for mutualistic interactions we set $C=0.002$ and $B=0.004$. That is, the benefit per 
unit joint wealth from mutualism is twice the cost. Later we shall explore (in one case only) what effect this choice for $B$ and $C$ has on the district. Similarly we set $c=0.001$, and later also explore what effect this choice of parameter gives. Due to the number of model parameters such an analysis will by necessity not be rigorous and can only give suggestions as to the behaviour of the system in general.

To summarise, we shall run simulations for various values of $n s$ and $n c$, for each of the district types, and for various positions of the mutualistic or competitive connection. It would be very hard to find representative transient dynamics for all of these individual scenarios, and so we shall focus on the long term behaviour. From running the model on several different networks it seems that the district commonly transitions to a fixed point. That is, each firm has a constant utility in the long run. As this seems to be a common behaviour we shall use it to investigate the effect of the structural position of mutualism and competition. For each simulation, we store details on whether a fixed point is reached (before a specific cut-off time) so that we can check that the assumption of transition to a fixed point is indeed a valid one. The cut-off time is chosen so as to capture the final equilibrium, and retrospectively we check that there are no further effects on a longer timescale by running the simulation for three times this long. We also store details of what proportion of firms survive (have nonzero utility) at equilibrium and what the average utility of the surviving firms is. From this data we can work out the percentage change in how many firms survived at equilibrium and their average value when mutualism/competition is introduced compared to the baseline case without mutualism/competition, for each type of mutualisitic or competitive link position and each value of $n s$ and $n c$. These values are then aggregated to calculate the average (median) and spread of change for each position type (over variations in the number of suppliers and consumers). This data is presented using box and whisker diagrams, where the whiskers depict the range of the data.

\subsection{Marshallian District}

The effect of various positions of a competitive connection on the performance of a Marshallian district is shown in Figure 5. These results do not include the simulations where a long term equilibrium was not reached, which accounted for about $0.03 \%$ of the simulations run on Marshallian districts. For comparison, when a second ensemble of simulations that don't include mutualism or comparison was run, the median of percentage change in the proportion of firms surviving was zero, while the interquartile and full ranges were $[-1.05 \%, 1.05 \%]$ and $[-5.63 \%, 4.48 \%]$ respectively. The median of 
percentage change in the average value of surviving firms was zero, with interquartile and full ranges of $[-1.21 \%, 0.99 \%]$ and $[-4.23 \%, 6.66 \%]$.
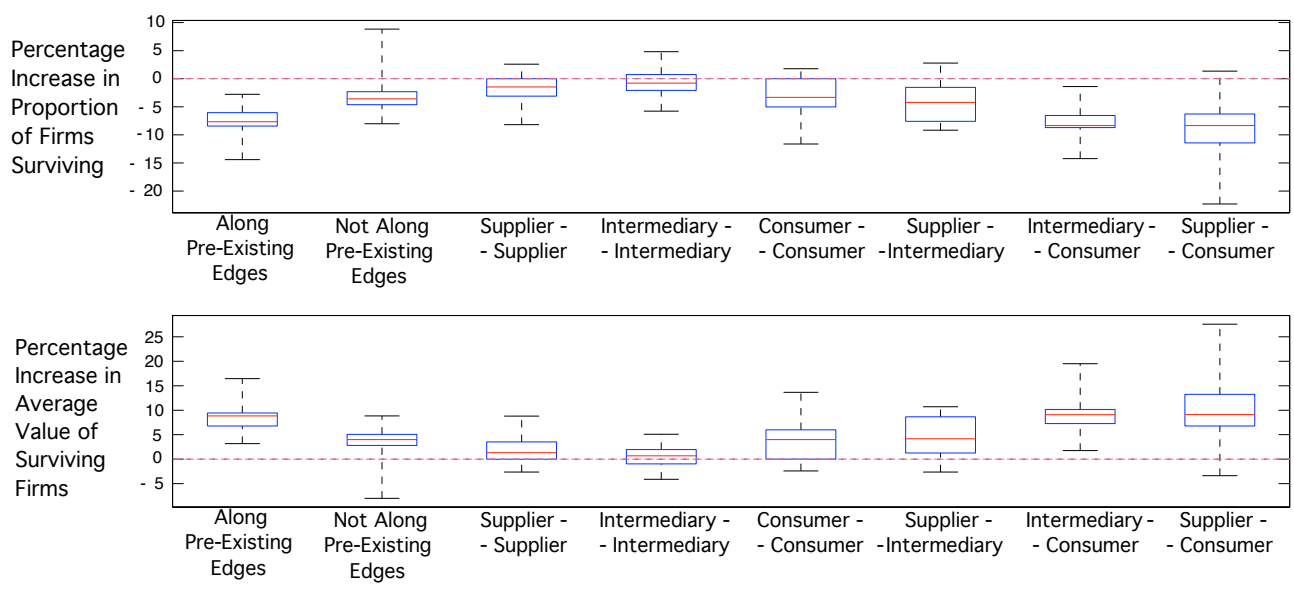

Figure 5: The effect on the long-term behaviour of the dynamics of industries in a Marshallian district of the addition of a competitive connection in various structural positions.

The first thing to notice is the similarity between all of the scenarios for the positioning of a competitive connection. The average effect is always to decrease the mean proportion of firms that survive and increase the mean wealth of surviving firms. Note that because we show the distribution over values of $n s$ and $n c$ of the means over an ensemble of 100 realisations for each combination of these values, we cannot deduce that mean wealth goes up when firm numbers go down. However, this is a likely scenario and does make sense: if two firms are in competition then if one of them thrives this has a detrimental effect on the other, meaning that there is an increased chance of that firm going bust. As the system as a whole is only constrained by the total external market demand, $M$, this could have the effect of driving up the average value of all the other firms.

However, apart from this similarity the most interesting things we can see from this figure are differences. For instance, there is a noticeable difference in the scale of the effect of a competitive relationship between firms in the same 'layer' and those in different 'layers'. For instance the percentage decrease in the number of firms surviving is smaller for supplier-supplier, and intermediary-intermediary competitive relationships than for supplierconsumer, and intermediary-consumer competitive relationships. This fact is probably the main reason that competition along pre-existing trade links has a more pronounced effect than competition that does not coincide with 
a trade link. Interactions along pre-existing trade links will be between different 'layers' whilst interactions which are not along a pre-existing trade link will be split between those within a 'layer' and those between 'layers'.

Another result to draw out is the danger (in terms of the number of firms surviving) in having a competitive relationship which involves an end consumer. Either as a supplier or intermediary it seems that the most pronounced effect comes from having a competitive connection with a consumer. This is probably due to the fact that the 'end consumer' is slightly worse off in terms of the external marketplace, meaning that the other 'end consumers' (and their suppliers) are likely to do better at the expense of the consumer (and its suppliers) in the competitive relationship. Thus the most pronounced effect in shaping the district is caused by competitive relationships along pre-existing trade links, between different'layers' of the network, and involving an end consumer.

We now move on to consider the effect of mutualistic relationships on the district. The results from our simulations are shown in Figure 6, As
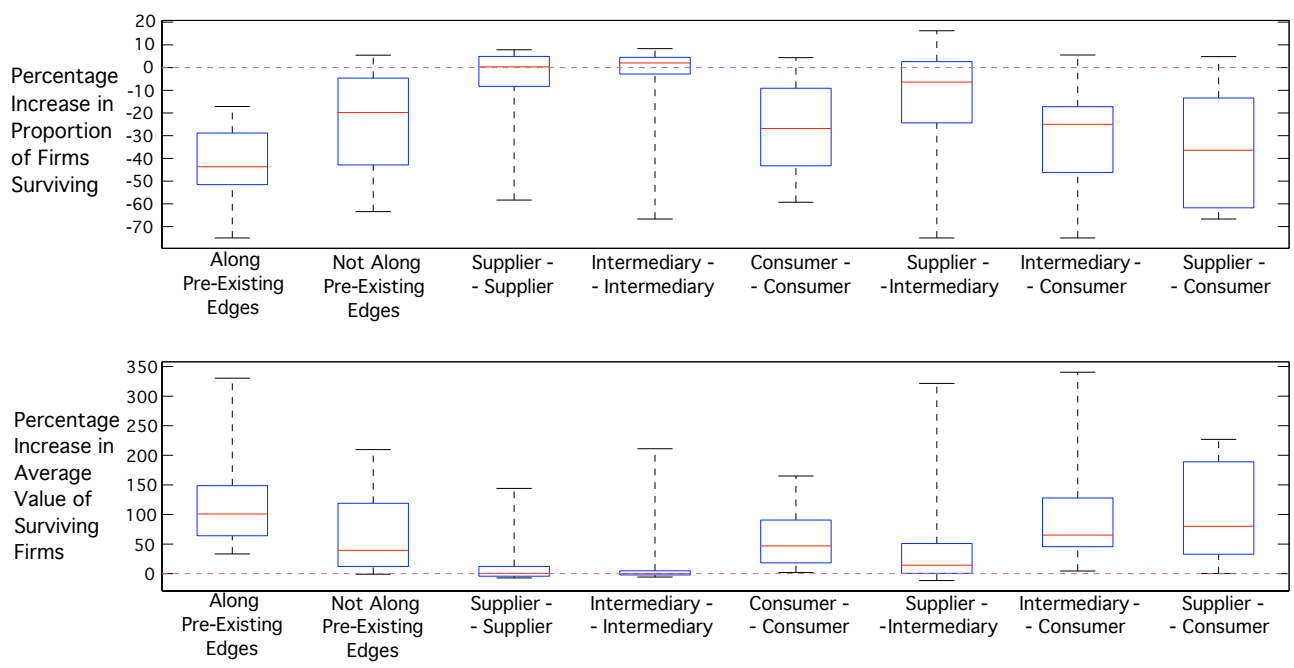

Figure 6: The effect on the long-term behaviour of the dynamics of industries in a Marshallian district of the addition of a mutualistic connection in various structural positions.

in the case of competition we again comment on the broad similarities first. For mutualistic connections it appears that these similarities are not as pronounced as for the competitive interactions. In fact the only similarity appears to be that the average value of the surviving firms is likely to increase, independent of the position of the mutualistic relationship.

The differences however are more pronounced and interesting. First of 
all the effect of a mutualistic relationship between two suppliers or two intermediaries seems to be special in that in most cases either the mean number of firms that the district can sustain or the average value of surviving firms or both increase, which could be viewed as a tendency to lead to a more 'egalitarian' district. This is the best possible scenario when considering the district as a whole.

On the other hand any mutualistic relationship involving an end consumer (almost) always causes a much larger rise in the wealth of the firms surviving in the district, however this is at the cost of the number of surviving firms decreasing. This makes sense, if an end consumer is in a mutualistic relationship then it has an advantage over the other end consumers in terms of the external market. As it is the capacity of the external market that constrains the district this leads to this end consumer, its suppliers, and its mutualistic partner performing better to the detriment of all other firms.

Thus, we have two distinct scenarios. For an egalitarian district, with capacity for more firms to survive and/or perform better, mutualistic relationships should be encouraged between primary suppliers, and between intermediaries. However from an individual (primary supplier or intermediary) firm's perspective the pay off in terms of wealth would probably be much greater if a mutualistic relationship were formed along a pre-existing link, between layers, and ideally with an end consumer. End consumers themselves should try to form mutualistic relationships with firms which directly supply them or with primary suppliers.

We can also compare the relative effect of mutualism and competition. Looking at Figures 5 and 6 together we can immediately observe that the effect of a mutualistic relationship is much more pronounced than the effect of a competitive relationship. This is particularly interesting when considering the average decrease in the percentage of firms surviving in the long term. Perhaps surprisingly, a mutualistic connection (on average) has a worse impact on the number of firms that the district supports in the long term than a competitive connection.

\subsection{Hub-and-Spoke District}

Moving on to hub-and-spoke trade networks (where all end consumers are supplied directly and only by the hub), we study the effect of the placement of a single competitive or mutualistic connection. For consistency with the analysis for Marshallian districts, when placing the mutualistic or competitive connection we count the hub as both a supplier and a consumer. So, for instance, a supplier-supplier connection may in fact be between a supplier and the hub. 
For comparison, when a second ensemble of simulations that don't include mutualism or competition was run, the median and full range of percentage change in the proportion of firms surviving was exactly zero and the median of percentage change in the average value of surviving firms was also zero, while the full range was $[-0.43 \%, 0.54 \%]$.
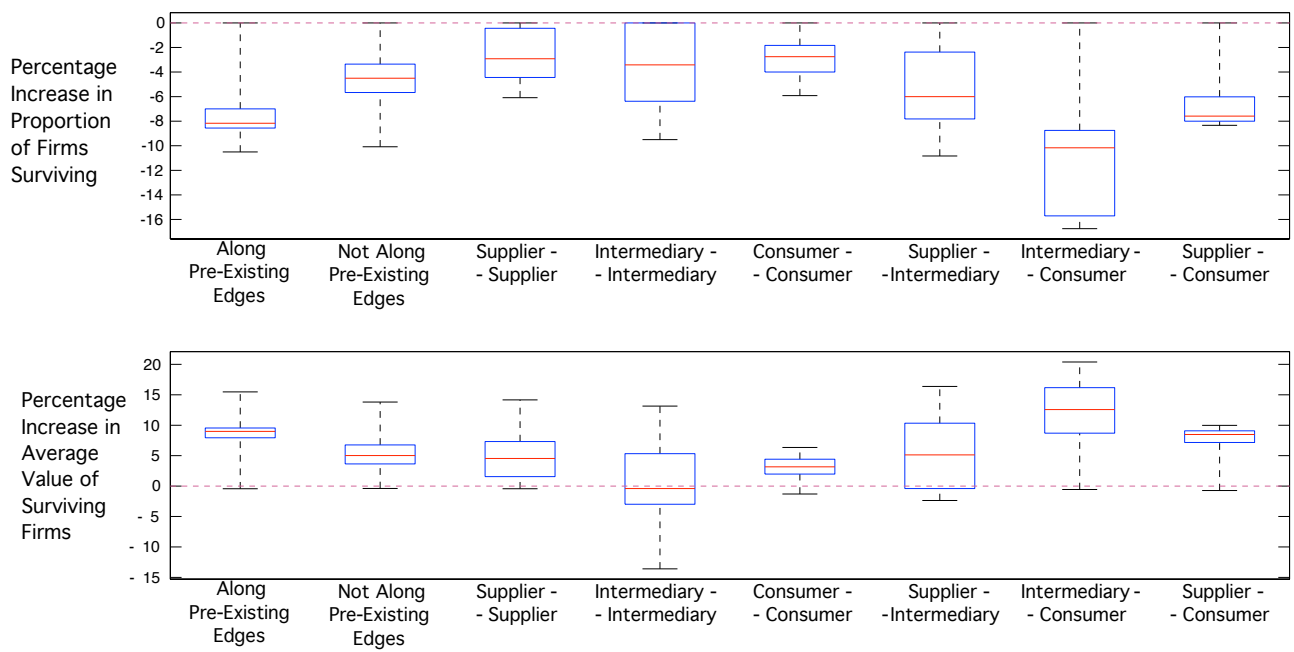

Figure 7: The effect on the long-term behaviour of the dynamics of industries in a hub-andspoke district of the addition of a competitive connection in various structural positions.

The output from running simulations of the model with a single competitive link is shown in Figure 7 . Note that all simulations run gave the long-term behaviour of a hub-and-spoke district as an equilibrium. The only major similarity that we see across all placement types is that the average number of firms surviving always decreases. With the exception of an intermediary-intermediary competitive connection this decrease in the mean number of firms surviving in the long term coincides with an increase in the average value of surviving firms. Again a resonable interpretation is that this is due to the district being constrained by the demand of the external market. The exception of the intermediary-intermediary interaction is very interesting. Here the typical change in the mean value of surviving firms is very slightly negative. Whilst in a substantial proportion of simulations the average value of surviving firms increases, over half of the time the average value decreased. This could be due to the fact that such competition is likely to reduce the flow of materials to the hub from two of its sources as well as the primary suppliers which supply them, creating a situation where the expansion of the hub is restricted. 
Another aspect of the output to highlight is the difference in magnitude between the effect of a competitive relationship between firms in the same 'layer' (e.g. supplier-supplier) and those in different 'layers' (e.g. intermediary-consumer). The effect, particularly in the decrease in the number of firms surviving in the long term, is much more pronounced for connections between firms in different 'layers' and for competition along preexisting trade links. The position of the median is closest for the increase in value for supplier-supplier and supplier-intermediary links, but the supplierintermediary link still gives a greater increase. This is likely to be due to a feedback effect, where a profitable firm ends up driving down the wealth of one of its (possibly indirect) suppliers and hence restricts its own supply in some way. This effect appears to be most pronounced when competition links an intermediary and an end consumer: we suggest that this is because such an interaction will always have a direct effect on the supply of material to the hub, and on its ability to sell within the district. As the hub is central to the district any impact on it will have an effect on the whole of the network.

Finally, we consider the effect of a mutualistic link on the dynamics of a hub-and-spoke district (Figure 8). As with the competitive link, it
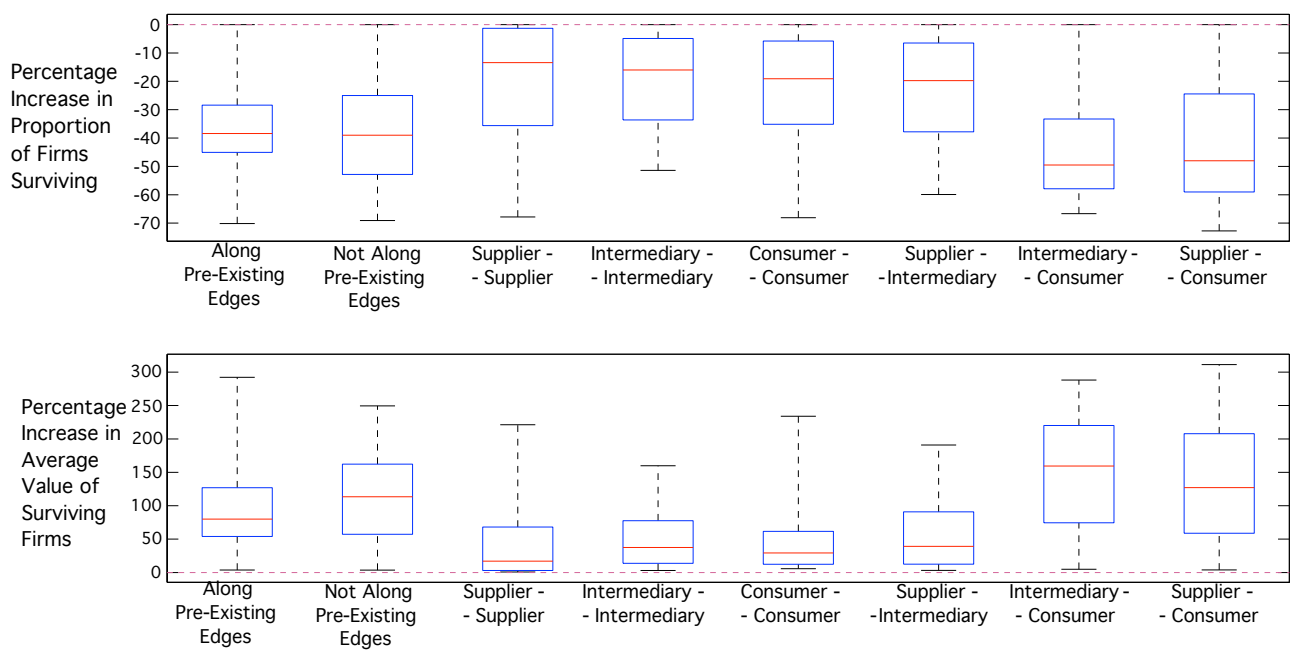

Figure 8: The effect on the long-term behaviour of the dynamics of industries in a hub-andspoke district of the addition of a mutualistic connection in various structural positions.

appears that the mean number of firms which survive in the long run always decreases, and this decrease always coincides with an increase in the average value of surviving firms. Unlike the competitive interaction there does not 
appear to be a clear dichotomy between the effect of a mutualistic connection between firms in the same 'layer' and those in different layers. It appears that the strongest effect comes from mutualism between layers where one of the partners is an end consumer. Generally the effect of mutualism between firms in the same layer is not as strong as those in different layers. However this is further complicated by the fact that the effect of mutualism which is not along a pre-existing trade connection is slightly stronger than the effect when it is along a pre-existing trade link. We believe that this is due to the fact that there are no trade interactions between the different supply chains of the hub. Thus a connection which is not along a pre-existing trade link is likely to couple two supply chains (or two customers of the hub, or a supply chain and a customer of the hub) meaning that there is a larger effect on the network than mutualism which just affects one chain. The only possible caveat to this is if the mutualistic relationship is along a trade link directly involved with the hub, in which case the direct effect on the hub will probably have a large knock-on impact on the rest of the district.

We can also compare the relative effects of mutualism and competition. The most prominent difference is again in the scale of the effect seen. A single mutualistic connection has a much stronger effect than a single competitive one. A mutualistic connection on average decreases the number of firms surviving by about 40 percent whilst competition only produces an average reduction of about 6 percent. This is perhaps a little surprising, as we might intuitively expect mutualism to have a lesser effect, in terms of reducing the number of firms that survive, than competition. However it is likely that the model is actually showing different firms being impacted in the two cases. For mutualism the firms that fail to survive are likely not to be partners in the mutualistic relationship, whilst for competition the firms in the competitive relationship are likely not to survive. This is due to mutualism broadly giving a firm an advantage relative to the rest of the district whilst competition broadly gives the firm a disadvantage.

\subsection{Comparison}

Having looked at the effects of mutualism and competition on Marshallian districts and hub-and-spoke districts separately we now compare the two, to emphasise the similarities and the differences. The most striking similarity is that in both district types mutualism had a much stronger effect than competition. This points to the importance of mutualistic relationships in shaping industrial districts. However, we stress that more complicated patterns of mutualistic and competitive relationships are likely to be subtler in their effects. In order to assess whether the stronger effect of mutualism 
could be an artefact of the parameters chosen for the strength of the mutualistic and competitive connections we look at one case chosen at random and vary these parameters $(B, C$ and $c)$. We do this for both the Marshallian and hub-and-spoke districts. We choose to look at districts with two suppliers, five intermediaries and five consumers. In the Marshallian case we also restrict to districts with twenty edges, as described earlier. We look at the effect on the percentage increase of firms surviving when a non-trade connection (mutualistic or competitive) is made along a pre-existing trade connection as the mutualism and competition parameters are varied. To do this we create several instances of the district for each parameter choice and then take the average. The average decrease in the percentage of firms which survive in the long run when a non-trade connection is added along a pre-existing trade link is shown in Figures 9 and 10 for Marshallian and hub-and-spoke districts respectively.
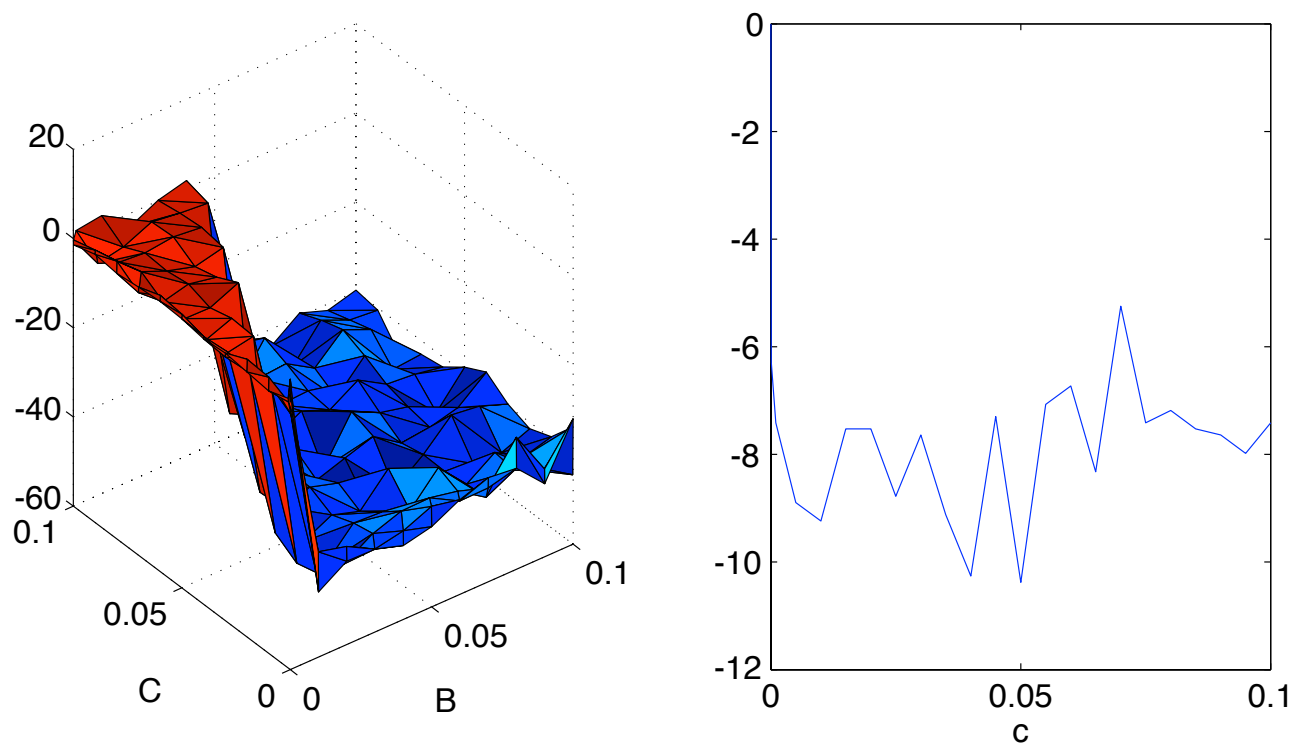

Figure 9: The effect on the percentage decrease of the average number of firms surviving of varying the mutualism and competition parameters for Marshallian districts (with two suppliers, five intermediaries, five consumers and twenty links) with a non-trade interaction along a pre-existing trade connection. Left panel: the mutualism parameters $(B$ and $C$ ) are varied. (Colour online: the surface is coloured according to its height, red being the highest points and blue the lowest.) Right panel: the competition parameter $(c)$ is varied.

From Figures 9 and 10 it appears to be generically true that mutualism has a stronger effect than competition when only a single non-trade connection is present. For the Marshallian district this is only not true when the 

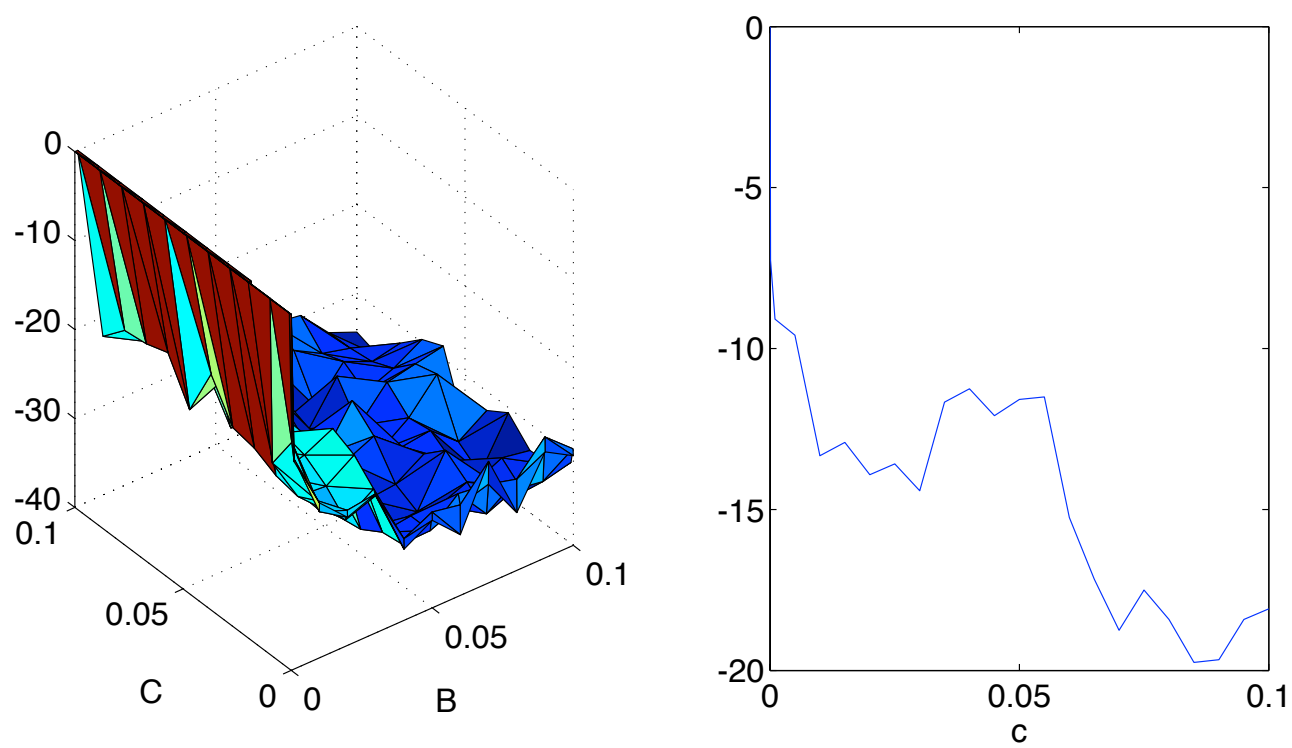

Figure 10: The effect on the percentage decrease of the average number of firms surviving of varying the mutualism and competition parameters for hub-and-spoke districts (with two suppliers, five intermediaries and five consumers) with a non-trade interaction along a pre-existing trade connection. Left panel: the mutualism parameters $(B$ and $C)$ are varied. (Colour online: the surface is coloured according to its height, red being the highest points and blue the lowest.) Right panel: the competition parameter $(c)$ is varied.

cost of mutualism is greater than the benefit (in which case it is not truly a mutualistic relationship). For hub-and-spoke districts it may only not be true if the competition parameter, $c$, is several orders of magnitude stronger than the mutualistic benefit parameter, $B$. Hence we highlight for further investigation the hypothesis that the effects of mutualism on an industrial district are more pronounced than those of competition.

Another similarity between the outcomes of adding a mutualistic or competitive connection in the two district types is that, in most cases, a decrease in the percentage of firms that survive occurred with a resulting increase in the health/wealth of these surviving firms.

Looking specifically at competition in the two district types, there were further similarities. Firstly the effect was more pronounced when the competitive relationship was between different 'layers' rather than within the same 'layer'. Furthermore a competitive relationship along a pre-existing trade link had a stronger effect than one that was not along a pre-existing trade connection. The notable similarity between the two industrial district types in the case of mutualism was that the most pronounced effect was 
caused by a mutualistic connection involving an 'end consumer'.

There were also several differences between the two district types in the effects of the non-trade relationships. For instance, in Marshallian districts there was the opportunity for a more egalitarian industrial district to arise from mutualism between suppliers and between intermediaries, with the mean percentage of firms that survive in the long run and the mean individual firm wealth both being likely to increase (though typically not both at the same time). In hub-and-spoke districts such an effect does not appear to be possible: neither mutualism nor competition can increase the average percentage of firms surviving in the long run.

Another difference between the district types is in the probability of decreasing the average utility of surviving firms. In a hub-and-spoke district a competitive relationship between intermediaries leads, on average, to a slight decrease in the value of the surviving firms, something that is not seen (on average) for any placements of competitive or mutualistic relationships in Marshallian districts.

The final point we wish to highlight is that the effect of non-trade relationships is typically stronger along pre-existing trade relationships. The exception is for mutualistic relationships in a hub-and-spoke network, where the mutualism couples disparate supply chains increasing both their chances of survival.

\section{Conclusion}

In this paper we set out to begin to investigate the effect of non-trade interactions on the performance of an industrial district. In order to do this we introduced a model of trade dynamics and extended it to incorporate dyadic interactions that were divided into two classes: mutualistic relationships that were beneficial to both parties involved, and competitive relationships that were detrimental to both parties. We investigated what impact a single non-trade relationship would have on the district as a whole for instances of two archetypal industrial districts: Marshallian and hub-and-spoke.

We found that, in general, both mutualistic and competitive relationships caused the number of firms that survive in a district in the long run to fall, whilst increasing the average value of the firms that did survive. We also discovered that the effect of a single mutualistic relationship was more pronounced than that of a single competitive relationship. In some circumstances a mutualistic relationship could be worse (in terms of the number of firms surviving) for the district as a whole than a competitive 
one. However, from an individual firm's perspective it was better to be in a mutualistic relationship than a competitive one.

We also investigated whether the position of the relationship made any difference to the effect on the district. To do this we looked at non-trade relationships between different classes of node, for instance between a primary supplier and an intermediary. We found that the position of the relationship did indeed make a difference to the outcome. In most instances this only affected the magnitude of the effect: for instance, a mutualistic relationship had the most effect if one of the partners was an end consumer, and a competitive relationship had the most effect if the competitors were in different structural classes (supplier, intermediary, consumer). However in some instances the position of a non-trade relationship produced a qualitatively different average outcome for the district. For instance in Marshallian districts with mutualism between suppliers or between intermediaries it was likely that the mean number of firms surviving in the long run actually increased and so did the mean wealth of surviving firms (although not by much, and only occasionally in the same realisations). Building such relationships thus provided an opportunity to make the industrial district more egalitarian. Conversely competition between intermediaries in a hub-and-spoke district led to the average of both the mean proportion of surviving firms and the mean value of surviving firms falling. That is, misplaced competition in a hub-and-spoke district could lead to lower diversity and/or lower utility of the district. This situation did not arise for the more interconnected Marshallian districts.

The model we have presented necessarily greatly simplifies the dynamics that would be present in any real-world industrial district, and so our results are only suggestive of how mutualism and competition might operate in real trade networks. However this initial study suugests that the effect of nontrade dynamics on industrial districts may be profound. We now intend to revisit the case study of the Humber region [51, 1, 42] to develop a more empirically based method for identifying and analysing the mutualistic and competitive non-trade interactions that are fundamental in that industrial district, in order to gain insight into what the future might hold as the system transitions to a bio-based economy. One intriguing possibility is that analysis may suggest mutualistic relationships that could be initiated to speed up (or slow down) such a transition. 


\section{Acknowledgements}

This work was supported by the Engineering and Physical Sciences Research Council [grant number EP/H021779/1] (Evolution and Resilience of Industrial Ecosystems, ERIE).

\section{References}

[1] A.S. Penn, C.J.K. Knight, D.J.B. Lloyd, D. Avitabile, K. Kok, F. Schiller, A. Woodward, A. Druckman, L. Basson, Participatory development and analysis of a fuzzy cognitive map of the establishment of a bio-based economy in the Humber region, PLoS ONE 8 (11) (2013). doi:10.1371/journal.pone.0078319.

[2] A. Markusen, Sticky places in slippery space: A typology of industrial districts, Economic Geography 72 (32) (1996) 293-313.

[3] R.A. Frosch, N.E. Gallopoulos, Strategies for manufacturing, Scientific American 261 (3) (1989) 144-152.

[4] L.W.Jelinski, T.E. Graedel, R.A. Laudise, D.W. McCall, C.K.N. Patel, Industrial ecology: concepts and approaches, Proceedings of the National Academy of Sciences 89 (3) (1992) 793-797.

[5] E.A. Lowe, L.K. Evans, Industrial ecology and industrial ecosystems, Journal of Cleaner Production 3 (1) (1995) 47-53.

[6] T.E. Graedel, On the concept of industrial ecology, Annual Review of Energy and the Environment 21 (1996) 69-98.

[7] R.P. Côté, T. Smolenaars, Supporting pillars for industrial ecosystems, Journal of Cleaner Production 5 (1-2) (1997) 67-74.

[8] T. Sterr, T. Ott, The industrial region as a promising unit for ecoindustrial development - reflections, practical experience and establishment of innovative instruments to support industrial ecology, Journal of Cleaner Production 12 (8-10) (2004) 947-965.

[9] R. van Berkel, D. van Beers, A. Bossilkov, Regional resource synergies for sustainable development: The case of kwinana, MATERIALS FORUM 30 (2006) 176-187.

[10] D. Gibbs, Industrial symbiosis and eco-industrial development: An introduction, Geography Compass 2 (4) (2008) 1138-1154. 
[11] W.S. Ashton, The structure, function and evolution of a regional industrial ecosystem, Journal of Industrial Ecology 13 (2009) 228-246.

[12] P.D. Jensen, L. Basson, M. Leach, Reinterpreting industrial ecology, 15 5 (2011) 680-692.

[13] J. Korhonen, F. von Malmborg, P.A. Strachan, J.R. Ehrenfeld, Management and policy aspects of industrial ecology: An emerging research agenda, Business Strategy and the Environment. 13 (2004) 289-305.

[14] J. Korhonen, J.-P. Snkin, Analysing the evolution of industrial ecosystems: Concepts and application, Ecological Economics 52 (2005) 169186.

[15] W.S. Ashton, Understanding the organization of industrial ecosystems, Journal of Industrial Ecology 12 (2008) 34-51.

[16] W.S. Ashton, A.C. Bain, Assessing the short mental distance in ecoindustrial networks, Journal of Industrial Ecology 16 (1) (2012) 70-82.

[17] C. Elton, Animal Ecology, Sidgwick and Jackson, London, 1927.

[18] H.W. Hunt, D.C. Coleman, E.R. Ingham, R.E. Ingham, E.T. Elliott, J.C. Moore, S.L. Rose, C.P.P. Reid, C.R. Morley, The detrital food web in a shortgrass prairie, Biology and Fertility of Soils 3 (1-2) (1987) 57-68. doi:10.1007/BF00260580.

URL http://dx.doi .org/10.1007/BF00260580

[19] J. Bascompte, C. J. Melin, E. Sala, Interaction strength combinations and the overfishing of a marine food web, Proceedings of the National Academy of Sciences of the United States of America 102 (15) (2005) 5443-5447. arXiv:http://www.pnas.org/content/102/15/5443.full.pdf+html, doi:10.1073/pnas.0501562102. URL http://www .pnas.org/content/102/15/5443.abstract

[20] R.M. May, Stability and complexity in model ecosystems, Princeton University Press (Princeton, NJ), 1973.

[21] G. Caldarelli, P. G. Higgs, A. J. McKane, Modelling coevolution in multispecies communities, Journal of Theoretical Biology 193 (2) (1998) $345-358$. 
[22] R.V. Sole, J.M. Montoya, Complexity and fragility in ecological networks, Proceedings of the Royal Society of London. Series B: Biological Sciences 268 (1480) (2001) 2039-2045.

[23] P.E. Anderson, H.J. Jensen, Network properties, species abundance and evolution in a model of evolutionary ecology, Journal of Theoretical Biology 232 (4) (2005) 551-558.

[24] C. Fontaine, P. R. Guimarães Jr, S. Kéfi, N. Loeuille, J. Memmott, W. H. van der Putten, F. J. van Veen, E. Thébault, The ecological and evolutionary implications of merging different types of networks, Ecology letters 14 (11) (2011) 1170-1181.

[25] A. Mougi, M. Kondoh, Diversity of interaction types and ecological community stability, Science 337 (6092) (2012) 349-351.

[26] M.R. Chertow, Industrial symbiosis: Literature and taxonomy., Annual Review of Energy and the Environment (2000) 313-337.

[27] P.D. Jensen, L. Basson, E. E. Hellawell, M. R. Bailey, M. Leach, Quantifying geographic proximity: Experiences from the United Kingdoms National Industrial Symbiosis Programme., Resources, Conservation and Recycling 55 (2011) 703-712.

[28] D.R. Lombardi, P. Laybourn, Redefining industrial symbiosis: crossing academic-practitioner boundaries, Journal of Industrial Ecology 16 (1) (2012) 28-37.

[29] B.D. Martin, E. Schwab, Current usage of symbiosis and associated terminology, International Journal of Biology 5 (1) (2013) 32-45.

[30] S. Kraines, D. Wallace, Applying agent-based simulation in industrial ecology, Journal of Industrial Ecology 10 (1-2) (2006) 15-18.

[31] D.F. Batten, Fostering industrial symbiosis with agent-based simulation and participatory modeling, Journal of Industrial Ecology 13 (2) (2009) 197-213.

[32] K. Cao, X. Feng, H. Wan, Applying agent-based modeling to the evolution of eco-industrial systems, Ecological Economics 68 (11) (2009) $2868-2876$.

[33] E.J.L. Chappin, G.P.J. Dijkema, Agent-based modelling of energy infrastructure transitions, International journal of critical infrastructures 6 (2) (2010) 106-130. 
[34] C.R. Binder, C. Hofer, A. Wiek, R.W. Scholz, Transition towards improved regional wood flows by integrating material flux analysis and agent analysis: the case of Appenzell Ausserrhoden, Switzerland, Ecological Economics 49 (1) (2004) 1-17.

[35] P.-M. Boulanger, T. Bréchet, Models for policy-making in sustainable development: The state of the art and perspectives for research, Ecological Economics 55 (3) (2005) 337-350.

[36] C. Davis, I. Nikolić, G.P.J. Dijkema, Integration of life cycle assessment into agent-based modeling, Journal of Industrial Ecology 13 (2) (2009) 306-325.

[37] J. Beck, R. Kempener, B. Cohen, J. Petrie, A complex systems approach to planning, optimization and decision making for energy networks, Energy policy 36 (8) (2008) 2795-2805.

[38] R. Kempener, J. Beck, J. Petrie, Design and analysis of bioenergy networks: a complex systems approach, Journal of Industrial Ecology 13 (2) (2009) 284-305.

[39] W. Ashton, Understanding the organization of industrial ecosystems: a social network approach, Journal of Industrial Ecology 12 (1) (2008) $34-51$.

[40] R.L. Paquin, J. Howard-Grenville, Facilitating regional industrial symbiosis: Network growth in the uk's national industrial symbiosis programme, in: F.A. Boons, J. Howard-Grenville (Eds.), The Social Embeddedness of Industrial Ecology, Edward Elgar Publishing, London, UK, 2009.

[41] R. L. Paquin, J. Howard-Grenville, The evolution of facilitated industrial symbiosis, Journal of industrial Ecology 16 (1) (2012) 83-93.

[42] A.S. Penn, P.D. Jensen, A. Woodward, L. Basson, F. Schiller, A. Druckman, Sketching a network portrait of the humber region, Complexitydoi:10.1002/cplx.21519.

[43] F. Boons, W. Spekkink, Y. Mouzakitis, The dynamics of industrial symbiosis: a proposal for a conceptual framework based upon a comprehensive literature review, Journal of Cleaner Production 19 (9) (2011) 905-911. 
[44] C. Hardy, T.E. Graedel, Industrial ecosystems as food webs, Journal of Industrial Ecology 6 (1) (2002) 29-38.

[45] E. Thébault, C. Fontaine, Stability of ecological communities and the architecture of mutualistic and trophic networks, Science 329 (5993) (2010) 853-856. doi:10.1126/science.1188321.

[46] M. Mirata, Experiences from early stages of a national industrial symbiosis programme in the uk: determinants and coordination challenges, Journal of Cleaner Production 12 (8) (2004) 967-983.

[47] A.J. Lotka, Elements of Physical Biology, Williams and Wilkins, 1925.

[48] W.W. Murdoch, C.J. Briggs, R.M. Nisbet, Consumer-Resource Dynamics, Vol. 36 of Monographs in Population Biology, Princeton University Press, 2003.

[49] P. Turchin, Complex Population Dynamics, A Theoretical/Empirical Synthesis, Vol. 35 of Monographs in Population Biology, Princeton University Press, 2003.

[50] W.P. Barnett, G.R. Carroll, Competition and mutualism among early telephone companies., Administrative Science Quarterly 32 (3).

[51] C.J.K. Knight, A.S. Penn, R.B. Hoyle, A dynamical model of the industrial economy of the humber region, preprint arXiv:1404.3167. 